\title{
Differences in serum zinc levels in acutely ill and remitted adolescents and young adults with bulimia nervosa in comparison with healthy controls - a cross-sectional pilot study
}

\author{
This article was published in the following Dove Press journal: \\ Neuropsychiatric Disease and Treatment \\ 17 October 2017 \\ Number of times this article has been viewed
}

Florian D Zepf, ${ }^{1,2}$ Pradeep Rao, ${ }^{1,3}$ Kevin Runions, ${ }^{3,4}$ Richard M Stewart,' Julia K Moore, ${ }^{1,5}$ Janice WY Wong, ${ }^{1,4}$ Maike Linden, ${ }^{1,2,6}$ Idil Sungurtekin, ${ }^{7}$ Franziska Glass, ${ }^{8}$ Linda Gut, ${ }^{8}$ Dirk Peetz, ${ }^{9,10}$ Gudrun Hintereder, ${ }^{11}$ Michael Schaab, ${ }^{12}$ Fritz Poustka, ${ }^{8}$ Lars Wöckel ${ }^{8,13}$

'Centre and Discipline of Child and Adolescent Psychiatry, Psychosomatics and Psychotherapy, University of Western Australia, ${ }^{2}$ Specialised Child and Adolescent Mental Health Services (CAMHS), Department of Health in Western Australia, ${ }^{3}$ Community Child and Adolescent Mental Health Services, Department of Health in Western Australia, ${ }^{4}$ Telethon Kids Institute, University of Western Australia, ${ }^{5}$ Paediatric ConsultationLiaison Program, Child and Adolescent Mental Health Services, Department of Health in Western Australia, Perth, WA, Australia; ${ }^{6}$ Clinic for Child and Adolescent Psychiatry, Psychosomatics and Psychotherapy, RWTH Aachen University, Aachen, ${ }^{7}$ Department of Child and Adolescent Psychiatry and Psychotherapy, Central Institute of Mental Health, Mannheim, ${ }^{8}$ Department of Child and Adolescent Psychiatry, Psychosomatics and Psychotherapy, Goethe University, Frankfurt am Main, ${ }^{9}$ Institute of Laboratory Medicine, HELIOS Klinikum Berlin-Buch, Berlin, ${ }^{10}$ Department of Clinical Chemistry and Laboratory Medicine, University Center of the Johannes Gutenberg University Mainz, Mainz, "Department of Laboratory Medicine, Goethe University, Frankfurt am Main, ${ }^{12}$ Institute of Laboratory Medicine, Clinical Chemistry and Molecular Diagnostics, University of Leipzig, Leipzig, Germany; ${ }^{13}$ Center of Child and Adolescent Psychiatry and Psychotherapy, Clienia Littenheid AG, Littenheid, Switzerland

Correspondence: Florian D Zepf Centre and Discipline of Child and Adolescent Psychiatry, Psychosomatics and Psychotherapy, University of Western Australia, 35 Stirling Highway (M56I), Crawley, Perth, WA 6009, Australia Tel +6I 863895800 Email florian.zepf@uwa.edu.au
Background: Research has implicated that changes in zinc $(\mathrm{Zn})$ metabolism may be associated with the biological underpinnings of eating disorders, in particular anorexia nervosa. However, to date research on the role of $\mathrm{Zn}$ in patients with bulimia nervosa $(\mathrm{BN})$ is scarce.

Objective: We aimed to explore serum $\mathrm{Zn}$ concentrations in young patients with $\mathrm{BN}$, with a focus on the stage of the disorder, comparing acutely ill and recovered patients with $\mathrm{BN}$ with healthy controls.

Methods: Serum Zn concentrations were obtained from healthy controls and from acutely ill and remitted young patients with BN. Mean duration of remission was $4.0 \pm 3.5$ years.

Results: Remitted patients showed elevated serum $\mathrm{Zn}$ concentrations when compared to controls (Cohen's d=2.022), but concentrations were still in the normal range. Acutely ill patients also had higher serum $\mathrm{Zn}$ levels when compared to controls (all values still being within the reference range, Cohen's d=0.882). There was no difference between acutely ill and remitted patients with $\mathrm{BN}$ in serum $\mathrm{Zn}$ concentrations. Of note, remitted patients had a significantly higher body weight when compared to the other two groups. Overall, there were no significant differences in dietary preferences with regard to $\mathrm{Zn}$ containing foods between the groups.

Conclusion: The present study provides preliminary evidence that the underlying factors for changes in $\mathrm{Zn}$ serum concentrations in young patients with BN do not vary with regard to the stage of illness (acute versus remitted BN). Further prospective research is needed in order to disentangle the possible interplay between serum $\mathrm{Zn}$ status and bulimic eating behaviors.

Keywords: bulimia nervosa, zinc, serum concentrations, remission, eating disorders

\section{Plain language summary}

Changes in zinc (Zn) metabolism may be associated with anorexia nervosa (AN) but literature on bulimia nervosa $(\mathrm{BN})$ is scarce. We aimed to explore serum $\mathrm{Zn}$ concentrations in young patients with $\mathrm{BN}$, with a focus on the stage of the disorder (acutely ill and remitted). Remitted patients (those who no longer had symptoms of $\mathrm{BN}$ ) showed elevated serum $\mathrm{Zn}$ concentrations when compared to controls but concentrations were in the normal range. Acutely ill patients had higher serum $\mathrm{Zn}$ levels when compared to controls. There was no difference in serum $\mathrm{Zn}$ concentrations between acutely ill and remitted patients. Remitted patients had a significantly higher body weight. There were no significant differences in dietary preferences with regard to $\mathrm{Zn}$ containing foods between groups. The study provides preliminary evidence that changes in $\mathrm{Zn}$ serum concentrations in young patients with $\mathrm{BN}$ do not vary with the stage of illness. Further prospective research is needed to understand the relationship between serum $\mathrm{Zn}$ and $\mathrm{BN}$. 


\section{Introduction}

A role for $\mathrm{Zn}$ was suggested in the underlying pathophysiology ofAN over 35 years ago. ${ }^{1,2}$ While early observations of potential clinical beneficial effects of $\mathrm{Zn}$ supplementation ${ }^{3}$ in patients with AN have been replicated by other studies, ${ }^{4,5}$ the role of $\mathrm{Zn}$ in patients with eating disorders such as $\mathrm{AN}$ and $\mathrm{BN}$ is not fully understood. As far as patients with AN are concerned, two double-blind studies ${ }^{6,7}$ suggested that $\mathrm{Zn}$ supplementation could have beneficial effects on body mass index (BMI) in patients with $\mathrm{AN}$, and it was argued by some researchers that $\mathrm{Zn}$ supplementation might even be discussed as routine treatment in patients with $\mathrm{AN} .^{8}$

However, the literature available so far on Zn deficiency and related supplementation in patients with AN is by no means consistent, in particular with some studies ${ }^{9,10}$ refuting the findings on potential $\mathrm{Zn}$ deficiency, as well as the benefit of routine $\mathrm{Zn}$ supplementation in patients with AN. One reason suggested for this observed discrepancy is that there is currently no single universally accepted measure for assessing $\mathrm{Zn}$ status in the human population. ${ }^{11} \mathrm{~A}$ systematic review $^{12}$ of the methods of assessing zinc status in humans showed that plasma, urinary, and hair zinc were all reliable biomarkers of $\mathrm{Zn}$ status in healthy individuals, with all three responding to dietary manipulation. Notably, the review included studies on healthy individuals only and did not include other factors that may impact on zinc concentrations, such as infection, inflammation, trauma, stress, and starvation. The authors also state that biomarkers of zinc status in other groups, such as infants and children, immigrant populations in Europe, and situations in which "general malnutrition is present" require further studies before recommendations on reliable biomarkers of $\mathrm{Zn}$ status can be made.

The available literature on $\mathrm{Zn}$ status in patients with $\mathrm{BN}$ is even sparser. Only two studies ${ }^{13,14}$ found preliminary evidence for $\mathrm{Zn}$ deficiency in patients with $\mathrm{BN}$. McClain et $\mathrm{al}^{14}$ evaluated serum and 24 hour urinary $\mathrm{Zn}$ values in 12 healthy volunteers and 33 patients with an eating disorder ( $\mathrm{AN}$ and $\mathrm{BN}$ ). They measured these parameters before and after hospitalization, during which the subjects received either $\mathrm{Zn}$ supplementation ( $\mathrm{Zn} 75 \mathrm{mg}$ / day) or a placebo. Patients with BN had lower serum $\mathrm{Zn}$ concentrations and lower admission urinary $\mathrm{Zn}$ levels. During hospitalization, the authors found that serum Zn concentrations increased significantly compared to placebo in all supplemented patients with BN. Urinary $\mathrm{Zn}$ excretion also increased significantly in both patients with $\mathrm{BN}$ supplemented with $\mathrm{Zn}$ and also in the placebo group. They concluded that patients with an eating disorder showed biochemical evidence of $\mathrm{Zn}$ deficiency as assessed by serum or urinary $\mathrm{Zn}$. They postulated that inadequate dietary intake of $\mathrm{Zn}$ was a major contributory factor. Humphries et al ${ }^{13}$ reported that $40 \%$ of patients with BN met the biochemical criteria (measured by serum $\mathrm{Zn}$ and 24 hour urine $\mathrm{Zn}$ concentrations) for $\mathrm{Zn}$ deficiency, and hypothesized that $\mathrm{Zn}$ deficiency could be secondary to an eating disorder, and that this deficiency played a role in the chronicity of the disorder.

In the light of these preliminary findings, aspects related to dietary preferences and food intake have also received research attention. A study looking at nutritional intakes of women with $\mathrm{BN}$ showed that $70 \%$ of women had less than two thirds of the recommended daily allowance of $\mathrm{Zn}$ intake during non-binge episodes. ${ }^{15}$ In view of these findings, the authors of this study expressed concerns that if $\mathrm{Zn}$ was not an ingredient or part of the food intake related to bingeing, a significant $\mathrm{Zn}$ deficiency could result.

With regard to $\mathrm{Zn}$ supplementation in patients with $\mathrm{BN}$, it was shown to result in a significant improvement in reduction of "fat anxiety" and "weight vigilance" on the Multidimensional Body-Self Relations Questionnaire, as well as the "drive for thinness" and "body dissatisfaction" on the Eating Disorder Inventory (EDI). ${ }^{16}$

However, to date, there are few studies which assess serum $\mathrm{Zn}$ concentration in young patients with BN. Additionally, few studies take the stage of illness (acutely or remitted) into account. Consequently, the present study aimed to assess serum $\mathrm{Zn}$ concentrations in adolescent female patients with BN. Based on the existing literature, we expected that patients with $\mathrm{BN}$ would display lower serum $\mathrm{Zn}$ concentrations when compared to controls. We also aimed to examine, within an exploratory approach, any potential differences in serum $\mathrm{Zn}$ concentrations between acutely ill and recovered patients with BN.

Leptin is a hormone mainly produced by adipocytes and acts as an efferent satiety signal by virtue of its action on the leptin receptor in the hypothalamus. ${ }^{17}$ Zinc has been shown to affect serum leptin levels. Mantzoros et a $1^{18}$ showed that leptin levels decrease in response to zinc depletion and increase with zinc supplementation. This study also showed that the magnitude of leptin level changes was proportional to the changes of cellular zinc. We therefore additionally aimed to explore if there were any correlations between the leptin axis (leptin, soluble leptin receptor [sOB-R], and free leptin index [FLI]) and $\mathrm{Zn}$ serum concentrations in patients with BN. 


\section{Methods}

\section{Study sample}

The relevant Ethics Committee (Faculty of Medicine at JW Goethe University, Frankfurt am Main, Germany) assessed and approved the study. The present investigation was carried out in accordance with the Helsinki Declaration. All participants/their parents or guardians provided written informed consent for the study. A total of 36 female subjects (healthy controls: $n=13$, acutely ill patients with BN: $n=11$, remitted patients with BN: $n=12$ ) took part in the present investigation. The control group of the present study was also part of previous investigations. ${ }^{19,20}$ Data on weight, height, and BMI as well as blood samples were obtained at a major child and adolescent psychiatric hospital, and all participants from the acutely ill patient group were outpatients or inpatients at the hospital. Participants from the remitted group of patients with $\mathrm{BN}$ were former patients of the outlined mental health service who had been contacted via letter. The complete characteristics of the respective subgroups related to the present study are given in Table 1.

International Classification of Diseases-10th revision criteria for $\mathrm{BN}$ were fulfilled in the group of acutely ill patients. Subjects of the remitted group reported regular menses, presented with a BMI $>18 \mathrm{~kg} / \mathrm{m}^{2}$, reported no symptoms on the self-rating questionnaire of the structured interview for $\mathrm{AN}$ and BN (SIAB-S), ${ }^{21-23}$ showed normal weight, and reported no bingeing or vomiting for $>12$ months. The mean period of remission was $4.0 \pm 3.5$ years. As outlined elsewhere, ${ }^{19,20}$ a control group comprising students (secondary schools, medical students, and associated staff of the outlined mental health service) was recruited. Subjects allocated to the control group did not report any symptoms of an eating disorder or other psychiatric disorders (assessment was performed using the SIAB-S) and reported normal menses. In addition to the SIAB-S, the EDI Symptom Checklist ${ }^{24}$ was used in all participants. Depending on the age of the subjects, the Youth Self-Report Form (YSR) ${ }^{25}$ or the Adult Self-Report Form $(\mathrm{ASR})^{26}$ was administered in order to assess further aspects of possible psychopathological problems; controls that showed clinical abnormalities in the respective YSR and ASR subscales were excluded from the study. Dietary preferences (frequency but not quantity with regard to food practice and choice of foods) were assessed using an eight-point Likert scale in all participants (self-report). Moreover, subjects with previous and current somatic diseases (ie, diabetes, etc), acute or recent infections, or with abnormal thyroid hormones, liver enzymes, and electrolytes were excluded from the present study. For information on the use of medications and dietary supplements, see the Supplementary materials.

\section{Assessment}

Controls and remitted patients visited the hospital once for assessment. After admission, blood samples for the assessment of $\mathrm{Zn}$ status were obtained from acutely ill patients. As in our previous study, ${ }^{20}$ all samples were drawn between 2 and $6 \mathrm{pm}$ into trace mineral-free plastic tubes containing $2 \%$ sodium oxalate and were placed on ice (see Supplementary materials for details). Serum Zn concentrations were assessed using an atomic absorption spectrophotometer (PerkinElmer Inc, Waltham, MA, USA).

\section{Data analysis}

Data analysis was carried out using SPSS 22 statistics software (IBM Corporation, Armonk, NY, USA), and the normality of data was determined by applying the Kolmogorov-Smirnov goodness of fit test. ${ }^{27}$ Data on serum $\mathrm{Zn}$ concentrations as well as on leptin levels, sOB-R, FLI values, $\mathrm{Ca}^{2+}$, and inorganic phosphate were all normally distributed within all respective subgroups, and for those parameters, between-group comparisons were performed using $t$-tests (independent groups, two-tailed). When comparing

Table I Characteristics of the subgroups of the study sample

\begin{tabular}{|c|c|c|c|c|c|c|}
\hline Variables & $\begin{array}{l}\text { Controls } \\
(n=13)\end{array}$ & $\begin{array}{l}\text { Bulimia nervosa } \\
\text { acute }(n=I I)\end{array}$ & $\begin{array}{l}\text { Bulimia nervosa } \\
\text { remitted }(n=12)\end{array}$ & $P_{1}$ & $P_{2}$ & $P_{3}$ \\
\hline Age (years) & $25.32 \pm 2.58$ & $20.08 \pm 2.85$ & $24.80 \pm 2.48$ & $<0.00 \mathrm{I}(\mathrm{t}=4.725)$ & ns & $<0.001(\mathrm{t}=4.245)$ \\
\hline Weight (kg) & $57.99 \pm 5.54$ & $57.96 \pm 4.55$ & $64.10 \pm 7.70$ & ns & $0.031(\mathrm{t}=2.291)$ & $0.032(\mathrm{t}=2.298)$ \\
\hline Height $(\mathrm{cm})$ & $167.12 \pm 5.36$ & $166.82 \pm 4.35$ & $168.92 \pm 5.93$ & ns & ns & ns \\
\hline BMI $\left(\mathrm{kg} / \mathrm{m}^{2}\right)$ & $20.78 \pm 2.03$ & $20.84 \pm 1.51$ & $22.36 \pm 2.16$ & ns & $0.077(\mathrm{t}=\mathrm{I} .889)$ & $0.065(\mathrm{t}=1.948)$ \\
\hline $\mathrm{Ca}^{2+}(\mathrm{mmol} / \mathrm{L})$ & $2.31 \pm 0.47$ & $2.3 I \pm 0.09$ & $2.36 \pm 0.07$ & ns & $0.057(\mathrm{t}=2.002)$ & ns \\
\hline Phosphate (mg/dL) & $3.47 \pm 0.48$ & $3.48 \pm 0.50$ & $3.78 \pm 0.75$ & ns & ns & ns \\
\hline
\end{tabular}

Notes: $P_{1}=$ Healthy controls versus acutely ill patients with bulimia nervosa, $P_{2}=$ healthy controls versus remitted patients with bulimia nervosa, $P_{3}=$ acutely ill versus remitted patients with bulimia nervosa. Data shown as mean \pm standard deviation.

Abbreviations: BMI, body mass index; ns, not significant. 
the different subgroups (controls, acutely ill, and remitted patients with $\mathrm{BN}$ ) on different laboratory parameters (hormone levels, blood tests, etc) for controlling purposes, the data were also compared using $t$-tests (independent groups, two-tailed) if they were normally distributed. If the data were not normally distributed in one of the subgroups when two of the groups were compared pairwise, MannWhitney $U$ tests were performed (the complete data and results related to these controlling analyses are provided as Supplementary materials). If significant differences between groups were detected, Cohen's d-values were calculated as an estimate for effect sizes. Moreover, data and calculated effect sizes were used to perform post-hoc power analyses on serum Zn concentrations (an a priori power analysis was not possible because of no available pilot data). Post-hoc power analysis was performed using $\mathrm{G}^{*}$ Power Software, version 3.1.3C (Supplementary materials). ${ }^{28}$ Overall, as can be seen in more detail in the Supplementary materials, the present study was well-powered to detect differences in serum $\mathrm{Zn}$ concentrations between controls and acutely ill as well as remitted patients with $\mathrm{BN}$, but not for detecting differences between acutely ill and remitted subjects with regard to this parameter. Because no major between-group differences were found with regard to the leptin axis (see "Results" section), we also calculated post-hoc power based on Cohen's d-values in order to justify sample sizes for future large-scale research on leptin-related parameters. The level of statistical significance was set and kept at $P<0.05$. Because of the exploratory nature of the present study, significant results were not subjected to $\alpha$ adjustment in order not to obscure any potentially significant group differences.

\section{Results}

\section{Zn concentrations}

There was a significant difference in serum $\mathrm{Zn}$ concentrations, indicating that acutely ill patients had significantly higher Zn levels when compared with controls $(\mathrm{t}=2.152$, $P=0.043$, df $=1,22$ ). Moreover, remitted patients with $\mathrm{BN}$ also had significantly higher serum $\mathrm{Zn}$ concentrations when compared to controls $(\mathrm{t}=5.052, P=0.000, \mathrm{df}=1,23)$. There was no statistically significant difference in $\mathrm{Zn}$ concentrations between acutely ill and remitted patients with $\mathrm{BN}(\mathrm{t}=1.089$, $P=$ not significant $[\mathrm{ns}], \mathrm{df}=1,21)$. Results related to the serum $\mathrm{Zn}$ status of the different subgroups are given in Figure 1.

\section{Leptin axis}

Acutely ill patients with $\mathrm{BN}$ tended to show higher leptin concentrations when compared to healthy controls $(t=1.879$,

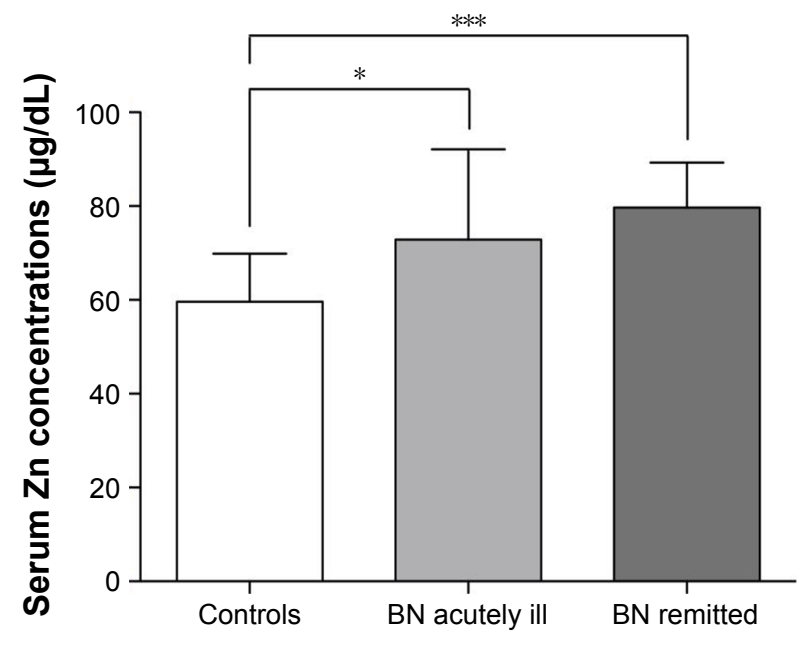

Figure I Comparison of serum Zn concentrations based on stage of illness. Note: $* P<0.05 ; * * * P<0.001$

Abbreviation: BN, bulimia nervosa.

$P=0.074, \mathrm{df}=1,22)$, though this did not reach conventional statistical significance. There was no difference in leptin concentrations between controls and remitted patients with BN $(\mathrm{t}=1.677, P=\mathrm{ns}, \mathrm{df}=1,23)$, as well as between acutely ill and remitted patients with $\mathrm{BN}(\mathrm{t}=0.118, P=\mathrm{ns}, \mathrm{df}=1,21)$. Moreover, there was no difference in sOB-R concentrations and FLI values between all groups. Table 2 presents a summary of all results related to the leptin axis and descriptive data.

\section{Effect sizes}

Cohen's d-values were calculated post-hoc as an estimate for the observed effect sizes. A d-value of 2.022 was found for the comparison of serum $\mathrm{Zn}$ concentrations between controls and remitted patients with $\mathrm{BN}$, whereas a d-value of 0.882 was observed for the comparison of serum $\mathrm{Zn}$ concentrations between healthy controls and acutely ill patients. Of note, for the comparison between acutely ill and remitted patients, a d-value of 0.455 was calculated although there were no statistically significant group differences.

\section{Discussion}

The present exploratory study compared serum Zn concentrations in acutely ill and remitted adolescent and young adult patients with $\mathrm{BN}$ and in controls of similar age. A post-hoc power analysis indicated that the study was adequately powered to detect differences between the control group and the two patient groups.

Serum $\mathrm{Zn}$ concentrations were significantly higher in acutely ill patients and remitted patients with $\mathrm{BN}$ when compared to controls. There were no significant differences between acutely ill and remitted patients with BN. In our 
Table 2 Means and standard deviations of concentrations of leptin, sOB-R, and FLI

\begin{tabular}{|c|c|c|c|c|c|c|}
\hline Index & $\begin{array}{l}\text { Controls } \\
(n=13)\end{array}$ & $\begin{array}{l}\text { Bulimia nervosa } \\
\text { acute }(n=I I)\end{array}$ & $\begin{array}{l}\text { Bulimia nervosa } \\
\text { remitted }(n=\mid 2)\end{array}$ & $P_{1}$ & $P_{2}$ & $P_{3}$ \\
\hline Leptin (ng/mL) & $8,4 \mid 3.77 \pm 4,597.36$ & $12,957.45 \pm 7,162.84$ & $|2,594.24 \pm 7,6| 7.89$ & $0.075(\mathrm{t}=\mathrm{I} .879)$ & ns & ns \\
\hline sOB-R (ng/mL) & $18.79 \pm 6.04$ & $22.20 \pm 5.66$ & $22.57 \pm 9.20$ & ns & ns & ns \\
\hline $\mathrm{FLI}$ & $0.53 \pm 0.43$ & $0.58 \pm 0.29$ & $0.63 \pm 0.48$ & ns & ns & ns \\
\hline
\end{tabular}

Notes: Data are presented for healthy controls as well as for acutely ill (bulimia nervosa acute) and remitted patients (bulimia nervosa remitted) with bulimia nervosa. $P_{1}=$ Healthy controls versus acutely ill patients with bulimia nervosa, $P_{2}=$ healthy controls versus remitted patients with bulimia nervosa, $P_{3}=$ acutely ill versus remitted patients with bulimia nervosa. Data shown as mean \pm standard deviation.

Abbreviations: sOB-R, soluble leptin receptor; FLI, free leptin index; ns, not significant.

earlier comparable study in patients with $\mathrm{AN},{ }^{20}$ serum $\mathrm{Zn}$ concentrations were significantly higher in remitted patients with AN, compared with acutely ill patients. Remitted patients with AN also showed higher serum Zn concentrations compared with controls.

Animal studies show that $\mathrm{Zn}$ deficiency is characterized by decreased food intake and a cyclic feeding pattern. ${ }^{29} \mathrm{Zn}$ deficiency is hypothesized to be a consequence of severe restriction of food intake in patients with AN. As per definition, the diagnosis of BN is not usually associated with starvation. Our finding that $\mathrm{Zn}$ levels were not lowered in patients with $\mathrm{BN}$ is contrary to the currently limited understanding of the pathophysiology of $\mathrm{BN}$ with regard to the role of $\mathrm{Zn}$, where $\mathrm{BN}$ is associated with lower $\mathrm{Zn}$ levels. ${ }^{13,14} \mathrm{Zn}$ levels are lower during non-binge episodes ${ }^{15}$ and return to normal upon supplementation. ${ }^{14}$

We found that remitted patients with BN had significantly higher weight and BMI values when compared to controls. One could speculate that the increased levels of serum $\mathrm{Zn}$ concentrations found in remitted patients with $\mathrm{BN}$ could be seen as a function of their higher weight ${ }^{6,8}$ and presumed higher nutrient intake. Of note, we did not find any differences in weight and BMI between acutely ill patients with $\mathrm{BN}$ and controls. Therefore, the higher levels of serum $\mathrm{Zn}$ concentrations in acutely ill patients with BN could possibly be related to a potential increased intake of $\mathrm{Zn}$ during binge eating, while body weight did not differ between acutely ill patients and controls. As reported previously in the literature,$^{15}$ the nutritional intake of $\mathrm{Zn}$ is lower in the non-binge periods, but it remains unclear if an increase in $\mathrm{Zn}$ levels may be achieved via a higher intake of food during periods of bingeing. It is possible, therefore, that $\mathrm{Zn}$ status in $\mathrm{BN}$ is better predicted by nutrient intake (eg, during starvation [non-binge episodes] versus bingeing) rather than by stage of the disorder (acute versus remitted). However, at this stage, such assumptions remain speculative and need to be confirmed by future large-scale prospective studies.

Serum leptin levels in acutely ill and remitted patients with $\mathrm{BN}$ appeared to trend toward increased levels when compared to controls, although this did not reach statistical significance. With regard to previous literature on $\mathrm{Zn}$-leptin interactions, it has been shown that circulating leptin concentrations are diminished during $\mathrm{Zn}$ deficiency in rats and humans. ${ }^{18,30}$ Various mechanisms including a decrease in the amount of leptin produced per gram of adipose tissue ${ }^{31}$ and an overall reduction in body fat during $\mathrm{Zn}$ deficiency ${ }^{32}$ have been proposed. This research, however, was based exclusively on animals and no human studies of this relationship exist. ${ }^{19}$ However, in our sample there were no significant associations or correlations between different parameters of the leptin axis (leptin, sOB-R, and FLI) and Zn serum concentrations, and further research on this subject is necessary, in particular with regard to younger patients and the developmental changes of the leptin axis.

In terms of potential clinical implications, no definite general conclusions regarding the value of $\mathrm{Zn}$ supplementation in patients with $\mathrm{BN}$ (both acutely ill and remitted) can be drawn. While past research has shown some preliminary value of $\mathrm{Zn}$ supplementation in patients with $\mathrm{BN},{ }^{16}$ the current results of the present study do not support this approach. However, from a clinical point of view, the potential benefits of $\mathrm{Zn}$ supplementation should still be evaluated for patients with a proven $\mathrm{Zn}$ deficiency.

\section{Limitations}

This study has a small sample size and although a post-hoc power analysis did show that the study was adequately powered to detect significant differences in the variables considered, one can only draw limited conclusions. The study did not consider effects of $\mathrm{Zn}$ supplementation in $\mathrm{BN}$ and larger-scale studies are needed to clarify both the above aspects. We did not consider nutritional intake nor did we classify $\mathrm{BN}$ based upon binge versus non-binge episodes that may indirectly indicate nutritional intake status. A future study may focus on this aspect to clarify our tentative conclusions in this regard. The small sample size also prevented us from assessing the impact of variables such as age and 
gender. The current literature on $\mathrm{Zn}$ status in BN is sparse and inconclusive as regards clinical applications and our study adds valuable data in this area. This study may also be the basis for future power calculations for future large-scale research in this area.

\section{Conclusion}

In summary, the present study found markedly higher serum $\mathrm{Zn}$ concentrations in acutely ill and remitted patients with BN when compared to controls. Future research on the underlying role of $\mathrm{Zn}$ metabolism in affected patients with $\mathrm{BN}$, in particular while controlling for a number of important covariates (body weight and BMI, frequency and magnitude of bingeing and vomiting behaviors, dietary preferences, distance from last meal, leptin axis functioning, age and developmental factors, etc), is necessary in order to further disentangle the mutual relationship between $\mathrm{Zn}$ status and the diagnosis of $\mathrm{BN}$. The results are contrary to previous studies suggesting lower serum $\mathrm{Zn}$ levels in $\mathrm{BN}$, but suggest that a nutritional status assessment including assessment of the status of binge versus non-binge episodes may be more useful when predicting $\mathrm{Zn}$ status in $\mathrm{BN}$ than the stage of the disorder.

\section{Acknowledgments}

The research leading to these results was funded by the Dannon Institute. The funding sources had no role in the writing of the manuscript or the decision to submit it for publication. JW Goethe University, Frankfurt am Main, Germany was the study site for this research.

\section{Disclosure}

FDZ was the recipient of an unrestricted award donated by the American Psychiatric Association (APA), the American Psychiatric Institute for Research and Education (APIRE) and AstraZeneca (Young Minds in Psychiatry Award). He has also received research support from the German Federal Ministry for Economics and Technology, the European Union (EU), the German Society for Social Paediatrics and Adolescent Medicine, the Paul and Ursula Klein Foundation, the Dr. August Scheidel Foundation, the IZKF fund of the University Hospital of RWTH Aachen University, the Telethon Kids Institute, the Telethon Perth Children's Hospital Research Fund, the Princess Margaret Hospital Foundation, and a travel stipend donated by the GlaxoSmithKline Foundation. He is the recipient of an unrestricted educational grant, travel support and speaker honoraria by Shire Pharmaceuticals, Germany. In addition, he has received support from the Raine Foundation for Medical Research (Raine Visiting
Professorship), and editorial fees from Co-Action Publishing (Sweden). The other authors declare that they have no competing interests.

\section{References}

1. Bakan R. The role of zinc in anorexia nervosa: etiology and treatment. Med Hypotheses. 1979;5(7):731-736.

2. Casper RC, Kirschner B, Jacob RA. Zinc and copper status in anorexia nervosa. Psychopharmacol Bull. 1978;14:53-55.

3. Safai-Kutti S, Kutti J. Zinc and anorexia nervosa. Ann Intern Med. 1984;100(2):317-318.

4. Bryce-Smith D, Simpson R. Case of anorexia nervosa responding to zinc sulphate. Lancet. 1984;324(8398):350.

5. Safai-Kutti S, Kutti J. Zinc therapy in anorexia nervosa. Am JPsychiatry. 1986;143(8):1059.

6. Birmingham CL, Goldner EM, Bakan R. Controlled trial of zinc supplementation in anorexia nervosa. Int J Eat Disord. 1994;15(3):251-255.

7. Katz RL, Keen CL, Litt IF, Hurley LS, Kellams-Harrison KM, Glader LJ. Zinc deficiency in anorexia nervosa. J Adolesc Health Care. 1987;8(5):400-406.

8. Birmingham CL, Gritzner S. How does zinc supplementation benefit anorexia nervosa? Eat Weight Disord. 2006;11(4):e109-e111.

9. Mira M, Stewart P, Abraham S. Vitamin and trace element status of women with disordered eating. Am J Clin Nutr. 1989;50(5):940-944.

10. Van Binsbergen C, Odink J, Van den Berg H, Koppeschaar H, Coelingh BH. Nutritional status in anorexia nervosa: clinical chemistry, vitamins, iron and zinc. Eur J Clin Nutr. 1988;42(11):929-937.

11. Wood RJ. Assessment of marginal zinc status in humans. J Nutr. 2000; 130(5):1350S-1354S.

12. Lowe NM, Fekete K, Decsi T. Methods of assessment of zinc status in humans: a systematic review. Am J Clin Nutr. 2009;89(6): 2040S-2051S.

13. Humphries L, Vivian B, Stuart M, McClain CJ. Zinc deficiency and eating disorders. J Clin Psychiatry. 1989;50(12):456-459.

14. McClain CJ, Stuart MA, Vivian B, et al. Zinc status before and after zinc supplementation of eating disorder patients. J Am Coll Nutr. 1992; 11(6):694-700.

15. Gendall KA, Sullivan PE, Joyce PR, Carter FA, Bulik CM. The nutrient intake of women with bulimia nervosa. Int J Eat Disord. 1997; 21(2):115-127.

16. Schauss A, Costin C. Zinc as a nutrient in the treatment of eating disorders. Am J Nat Med. 1997;4(10):8-13.

17. Zabeau L, Peelman F, Tavernier J. Leptin: from structural insights to the design of antagonists. Life Sci. 2015;140:49-56.

18. Mantzoros CS, Prasad AS, Beck FW, et al. Zinc may regulate serum leptin concentrations in humans. J Am Coll Nutr. 1998;17(3): $270-275$.

19. Zepf FD, Sungurtekin I, Glass F, et al. Differences in zinc status and the leptin axis in anorexic and recovered adolescents and young adults: a pilot study. Food Nutr Res. 2012;56.

20. Zepf FD, Sungurtekin I, Glass F, et al. Differences in serum Zn levels in acutely ill and recovered adolescents and young adults with anorexia nervosa-a pilot study. Eur Eat Disord Rev. 2012;20(3):203-210.

21. Fichter MM, Herpertz S, Quadflieg N, Herpertz-Dahlmann B. Structured interview for anorexic and bulimic disorders for DSM-IV and ICD-10: updated (third) revision. Int J Eat Disord. 1998;24(3):227-249.

22. Fichter M, Quadflieg N. Strukturiertes Inventar für anorektische und bulimische Eßstörungen:(SIAB); Fragebogen (SIAB-S) und Interview (SIAB-EX) nach DSM-IV und ICD-10 [Structured inventory for anorectic and bulimic eating disorders: (SIAB); Questionnaire (SIAB-S) and interview (SIAB-EX) according to DSM-IV and ICD-10]; Handanweisung. Göttingen: Hogrefe, Verlag für Psychologie; 1999. German.

23. Fichter M, Quadflieg N. The structured interview for anorexic and bulimic disorders for DSM-IV and ICD-10 (SIAB-EX): reliability and validity. Eur Psychiatry. 2001;16(1):38-48. 
24. Paul T, Thiel A. Eating Disorder Inventory-2 (EDI-2): deutsche Version. Göttingen: Hogrefe; 2005. German.

25. Achenbach TM. Manual for the Youth Self-Report and 1991 Profile. Burlington, VT: Department of Psychiatry, University of Vermont Burlington; 1991.

26. Achenbach T, Rescorla L. Manual for the ASEBA Adult Forms and Profiles. Burlington, VT: University of Vermont, Research Center for Children, Youth and Families; 2003.

27. Massey FJ Jr. The Kolmogorov-Smirnov test for goodness of fit. $J$ Am Stat Assoc. 1951;46(253):68-78.

28. Faul F, Erdfelder E, Buchner A, Lang A-G. Statistical power analyses using G* Power 3.1: tests for correlation and regression analyses. Behav Res Methods. 2009;41(4):1149-1160.
29. Selvais PL, Labuche C, Ninh NX, Ketelslegers JM, Denef JF, Maiter DM. Cyclic feeding behaviour and changes in hypothalamic galanin and neuropeptide $\mathrm{Y}$ gene expression induced by zinc deficiency in the rat. J Neuroendocrinol. 1997;9(1):55-62.

30. Shay NF, Mangian HF. Neurobiology of zinc-influenced eating behavior. J Nutr. 2000;130(5):1493S-1499S.

31. OttES, Shay NF. Zinc deficiency reduces leptin gene expression and leptin secretion in rat adipocytes. Exp Biol Med. 2001;226(9):841-846.

32. Mangian HF, Lee RG, Paul GL, Emmert JL, Shay NF. Zinc deficiency suppresses plasma leptin concentrations in rats. J Nutr Biochem. 1998; 9(1):47-51. 


\section{Supplementary materials Assessments}

The intra-assay imprecision was between $2.7 \%$ and $3.2 \%$, and the inter-assay imprecision was between $4.3 \%$ and $5.3 \%$ (normal range in adults: $70-120 \mu \mathrm{g} / \mathrm{dL}$; children and adolescents: 52-100 $\mu \mathrm{g} / \mathrm{dL}$; newborn: 60-90 $\mu \mathrm{g} / \mathrm{dL})$. These laboratory measurements were carried out at Johannes Gutenberg University. Routine laboratory tests (liver enzymes, thyroid function, inorganic phospate and electrolytes) were performed at the Department of Laboratory Medicine, JW Goethe University of Frankfurt am Main. We also measured leptin levels, soluble leptin receptor (sOB-R), free leptin index ([FLI] ratio between leptin and sOB-R levels) values, $\mathrm{Ca}^{2+}$ and inorganic phosphate. We also controlled for group differences with respect to calcium $\left(\mathrm{Ca}^{2+}\right)$ and other electrolytes as well as inorganic phosphate concentrations as $\mathrm{Ca}^{2+}$ and phosphorus were shown to have inhibitory effects on $\mathrm{Zn}$ absorption in humans..$^{5-7}$

\section{Use of medications and dietary supplementaries}

In the control group, four participants were taking dietary supplements which did not contain any Zn. ${ }^{1,2}$ One subject took iodide, one took thyroxine, one took pancreatin, and one took cholecalciferol. In the group of acutely ill patients with bulimia nervosa $(\mathrm{BN})$, some patients also received medications $(1 \times$ amitriptyline, $1 \times$ sertraline, $1 \times$ fluoxetine, $1 \times$ escitalopram, $1 \times$ citalopram, $1 \times$ methylphenidate, $1 \times$ lamotrigine), and four patients from this group took oral contraceptives. Moreover, in the group of acutely ill patients two patients took dietary supplements ( $1 \times$ magnesium, $1 \times$ vitamin $\mathrm{C}$ ), one patient took beclomethasone dipropionate for asthma, and one patient applied benzoyl peroxide cream for acne. In the group of remitted patients with $\mathrm{BN}$, one patient took fluoxetine and one patient took valproic acid. In addition, one patient took L-thyroxine and one patient took ciclesonide for asthma. With regard to dietary supplements, three remitted patients with BN took magnesium, and one patient took multivitamin tablets. Out of the group of remitted patients, a total of five patients took oral contraceptives. As lower serum $\mathrm{Zn}$ levels can be associated with intake of oral contraceptives, ${ }^{3,4}$ all subjects taking such medications were compared with those who did not. Comparisons indicated no significant differences between these two groups.

\section{Post-hoc power analysis}

A post-hoc power analysis was performed on the effects related to $\mathrm{Zn}$ serum concentrations, indicating that the present study had a power $(1-\beta)$ of 0.99 to detect significant differences with an effect size estimate (Cohen's d) as found in the present investigation between controls and remitted patients with BN with an $\alpha$-level of 0.95 . Moreover, statistical power was moderate with regard to the differences between healthy controls and acutely ill patients with $\mathrm{BN}$ ( power $=0.54, \alpha$-level $=0.95$, Cohen's $d=0.882$ ). With regard to the finding that there were no differences in serum $\mathrm{Zn}$ levels between acutely ill and remitted patients with $\mathrm{BN}$, it must be noted that the present study was not adequately powered to detect such a difference (power $=0.18, \alpha$-level $=0.95)$. With regard to leptin concentrations, the current study was adequately powered to detect differences between controls and acutely ill patients (power $=0.77$ ) as well as between controls and remitted patients (power $=0.67$ ), but not for the differences between acutely ill and remitted patients with BN. The results of the present study could serve as a foundation to calculate sample sizes for future large-scale research.

\section{Controlling variables}

In order to control for potential group differences with regard to hormones (luteinizing hormone [LH], follicle stimulating hormone [FSH], estrogen), different blood values (hemoglobin, hematocrit, erythrocytes, leucocytes, thrombocytes, mean corpuscular hemoglobin, mean corpuscular hemoglobin concentration, mean corpuscular volume, total bilirubin, urea and uric acid, inorganic phosphate, creatinine, albumin, total protein), electrolytes $\left(\mathrm{Na}^{+}, \mathrm{K}^{+}, \mathrm{Ca}^{2+}\right.$, $\mathrm{Cl}^{-}$), liver enzymes (glutamic oxaloacetic transaminase, glutamic pyruvic transaminase, gamma glutamyl transferase), enzymes (amylase, lipase, alkaline phosphatase), hormones (testosterone, LH, FSH, estrogen, cortisol) as well as cholesterol-related parameters (cholesterol, high density lipoprotein [HDL], low density lipoprotein, triglycerides) several between-group comparisons were performed for these parameters. When data were normally distributed, between-group two-tailed $t$-tests were used. For not normally distributed data, two-tailed Mann-Whitney $U$ tests were implemented for analyses.

\section{Controls versus acutely ill patients with $\mathrm{BN}$}

Acutely ill patients showed higher LH ( $\mathrm{t}=-2.751, P=0.012$, $\mathrm{df}=1,22)$ but lower HDL levels $(\mathrm{t}=2.467, P=0.022, \mathrm{df}=1,22)$ when compared to controls. There were no other differences to be found with regard to the other outlined controlling variables and blood values. 


\section{Controls versus remitted patients with $\mathrm{BN}$}

Remitted patients with $\mathrm{BN}$ showed higher FSH levels when compared to healthy controls ( $\mathrm{U}=-2.180, P=0.030$ ). Moreover, healthy controls had higher HDL values when compared to remitted patients with $\mathrm{BN}(\mathrm{t}=2.517$, $P=0.019$, df $=1,23$ ). There were no other differences detected.

\section{Acutely ill versus remitted patients with BN}

There were no significant group differences related to the outlined controlling variables.

\section{Impact of contraceptives}

To control for potential differences between participants who took contraceptives versus those who did not several between-group comparisons were performed for $\mathrm{Zn}$ serum concentrations as well as for parameters of the leptin axis (leptin, sOB-R, FLI). Normally distributed data were compared using between-group, two-tailed $t$-tests, not normally distributed data were compared using Mann-Whitney $U$ tests (two-tailed). There were no significant differences in serum $\mathrm{Zn}$ concentrations ( $\mathrm{t}=-1.165, P=$ not significant $[\mathrm{ns}]$, $\mathrm{df}=1,34)$, leptin ( $\mathrm{U}=-0.688, P=\mathrm{ns})$, sOB-R concentrations $(\mathrm{U}=-1.259, P=\mathrm{ns})$, and FLI $(\mathrm{U}=-0.302, P=\mathrm{ns})$.

\section{Dietary preferences}

An exploratory examination of remitted patients with $\mathrm{BN}$, acutely ill patients with $\mathrm{BN}$, and healthy control participants was conducted. This is shown in Table S1. Participants rated their liking of foods on a seven-point Likert scale. To reduce the number of comparisons, summary variables were constructed for meat (fish, meat, poultry, sausage; $\alpha=0.83$ ), vegetables (cauliflower, broccoli, white cabbage, chicory, endive, "vegetables", kale, radicchio, radish, spinach, asparagus, Brussel sprouts; $\alpha=0.77$ ), and deserts/sweet snacks (milk chocolate, cake, sweets; $\alpha=0.85$ ).

The final list of food preferences tested included these composite variables, along with preferences for white bread, whole wheat bread, black bread, pasta, whole wheat pasta, dumplings, soy products, white rice, brown rice, sauerkraut, sweetener, dark chocolate, cream, olives, French fries, cottage cheese, cheese, crispbreads, potatoes, fruit, grapefruit, oranges, and eggs. These were tested via multivariate analysis of variance, and Bonferroni correction was applied to correct for type 1 error arising from the large number of analyses. Thus, a significance level of $P<0.002$

Table SI Mean, variance and group differences in self-reported food preferences

\begin{tabular}{|c|c|c|c|c|c|}
\hline Food category & $\begin{array}{l}\text { Control } \\
(n=14)\end{array}$ & $\begin{array}{l}\text { Bulimia } \\
(n=9)\end{array}$ & $\begin{array}{l}\text { Remitted } \\
\text { bulimia }(n=I I)\end{array}$ & F-test & $\begin{array}{l}\text { Significance of } \\
\text { F-test (uncorrected) }\end{array}$ \\
\hline Meat & $3.42(1.6 I)$ & 2.17 (1.99) & $3.13(1.50)$ & 1.58 & 0.22 \\
\hline Vegetables & $\mathrm{I} .48(0.55)$ & $\mathrm{I} .62(0.78)$ & $1.66(0.73)$ & $\mathrm{I} .44$ & 0.25 \\
\hline Desserts/sweets & $4.06(1.38)$ & $3.52(1.45)$ & $2.94(1.46)$ & 1.87 & 0.17 \\
\hline White bread & 3.57 (I.75) & $3.67(2.60)$ & $2.00(1.84)$ & 0.34 & 0.71 \\
\hline Whole wheat bread & $3.79(2.23)$ & $4.33(1.94)$ & $4.45(1.57)$ & 0.41 & 0.67 \\
\hline Black bread & 2.36 (1.99) & 2.89 (1.69) & 2.82 (I.89) & 0.29 & 0.75 \\
\hline Crispbreads & $2.29(1.90)$ & 3.11 (2.89) & $0.91(0.83)$ & 3.24 & 0.05 \\
\hline Pasta & $4.43(0.94)$ & $4.00(1.80)$ & $4.45(0.93)$ & 0.43 & 0.65 \\
\hline Whole wheat pasta & 2.29 (I.77) & $2.67(2.50)$ & 3.45 (1.92) & 1.04 & 0.37 \\
\hline Dumplings & $\mathrm{I} .07$ (0.83) & $\mathrm{I} .00(0.87)$ & $\mathrm{I} .55(\mathrm{I} .04)$ & 1.15 & 0.33 \\
\hline Potatoes & $4.36(1.15)$ & $4.00(2.18)$ & $3.82(1.60)$ & 0.36 & 0.70 \\
\hline French fries & $2.14(1.4 I)$ & $1.67(1.4 \mathrm{I})$ & $\mathrm{I} .82(0.75)$ & 0.45 & 0.64 \\
\hline White rice & $3.14(1.56)$ & $4.33(1.94)$ & $3.73(1.85)$ & $\mathrm{I} .27$ & 0.30 \\
\hline Brown rice & 2.14 (1.75) & 4.67 (1.58) & 4.09 (1.58) & 7.64 & 0.002 \\
\hline Soy products & I.2I (1.97) & 1.67 (I.73) & $2.73(2.65)$ & $\mathrm{I} .54$ & 0.23 \\
\hline Olives & $2.14(2.58)$ & $2.67(2.86)$ & $3.32(2.06)$ & 0.68 & 0.52 \\
\hline Cottage cheese & 4.29 (1.59) & 4.33 (1.87) & $4.00(1.84)$ & 0.12 & 0.89 \\
\hline Cheese & $5.29(0.73)$ & $4.56(1.81)$ & $5.00(1.6 \mathrm{I})$ & 0.77 & 0.47 \\
\hline Fruit & $4.86(1.88)$ & 5.11 (1.97) & 5.45 (1.97) & 0.30 & 0.75 \\
\hline Grapefruit & I.I4 (I.79) & 1.78 (2.05) & 1.55 (I.64) & 0.36 & 0.70 \\
\hline Oranges & $2.50(1.5 \mathrm{I})$ & $4.22(2.17)$ & 3.55 (1.75) & 2.74 & 0.08 \\
\hline Eggs & 3.21 (1.48) & 3.22 (1.99) & $2.91(1.51)$ & 0.13 & 0.88 \\
\hline Dark chocolate & $2.00(2.00)$ & $\mathrm{I} .89$ (2.57) & $2.73(1.56)$ & 0.54 & 0.59 \\
\hline Sauerkraut & $0.86(0.95)$ & 1.78 (I.64) & $1.36(0.67)$ & 1.97 & 0.16 \\
\hline Cream & 2.14 (1.88) & I.II (I.I7) & I.82 (I.66) & $\mathrm{I} .08$ & 0.35 \\
\hline
\end{tabular}


was set as the criterion for statistical significance. None of the food preferences were significantly different across the three groups, with the exception of brown rice, with was significant at the criterion level $(P=0.002)$. Nonparametric post-hoc analyses (Dunnett $C$ ) indicated that both remitted $(\mathrm{M}=4.09, \mathrm{SD}=1.58)$ and acutely ill patients with $\mathrm{BN}$ $(\mathrm{M}=4.67, \mathrm{SD}=1.58)$ had stronger preferences for brown rice than did control participants $(\mathrm{M}=2.14, \mathrm{SD}=1.75)$. No other differences were found between control, acutely ill and remitted patients with $\mathrm{BN}$.

\section{References}

1. Zepf FD, Sungurtekin I, Glass F, et al. Differences in zinc status and the leptin axis in anorexic and recovered adolescents and young adults: a pilot study. Food Nutr Res. 2012;56.
2. Zepf FD, Sungurtekin I, Glass F, et al. Differences in serum Zn levels in acutely ill and recovered adolescents and young adults with anorexia nervosa-a pilot study. Eur Eat Disord Rev. 2012;20(3):203-210.

3. Akhter S, Shamsuzzaman A, Siddiqui N, Banerjee M, Deb K, Hossain M. Serum zinc status of rural women taking combined OC. Mymensingh Med J. 2005;14(2):128-132.

4. Fallah S, Sani FV, Firoozrai M. Effect of contraceptive pill on the selenium and zinc status of healthy subjects. Contraception. 2009;80(1):40-43.

5. Sandström B, Cederblad A, Stenquist B, Andersson H. Effect of inositol hexaphosphate on retention of zinc and calcium from the human colon. Eur J Clin Nutr. 1990;44(10):705-708.

6. Sandström B, Sandberg A-S. Inhibitory effects of isolated inositol phosphates on zinc absorption in humans. $J$ Trace Elem Electrolytes Health Dis. 1992;6(2):99-103.

7. Wood RJ, Zheng JJ. High dietary calcium intakes reduce zinc absorption and balance in humans. Am J Clin Nutr. 1997;65(6):1803-1809.

\section{Publish your work in this journal}

Neuropsychiatric Disease and Treatment is an international, peerreviewed journal of clinical therapeutics and pharmacology focusing on concise rapid reporting of clinical or pre-clinical studies on a range of neuropsychiatric and neurological disorders. This journal is indexed on PubMed Central, the 'PsycINFO' database and CAS, and is the official journal of The International Neuropsychiatric Association (INA). The manuscript management system is completely online and includes a very quick and fair peer-review system, which is all easy to use. Visit http://www.dovepress.com/testimonials.php to read real quotes from published authors. 